\title{
Effects of Gaming on Children's Brains: Depression and Social Isolation
}

\author{
Susan Landau, MA \\ California State University, Fullerton \\ Trent Nguyen, PhD \\ California State University, Fullerton
}

\begin{abstract}
This study documents the effects of gaming on children's brains, focusing on the negative effects of gaming, and in particular, social isolation and depression. Over the years, psychologists, parents and the general public have played a key role in advancing literature on gaming and brain development, thus enabling researchers to gain a deeper understanding of the adverse effects of excessive gaming. The main purpose of this study is to demonstrate that excessive gaming is strongly correlated with adverse effects such as social isolation and depression by reviewing various scholarly articles which clearly indicate that excessive gaming can derails a person's efforts to make real friends by affecting their social skills and making them aggressive. In the long run, children gamers become socially isolated. This paves way for depression and other selfharming habits. The methodology section justifies why the research had to be underlined by secondary research and secondary data. Results section reports actual findings on how gaming activates pleasure circuits to a certain degree, which leads to impulsive behavior that prevent children from engaging in active social lives.
\end{abstract}

Like any other artistic medium and cultural phenomenon introduced in the past 30 years, gaming is a habitual activity that has become an increasingly prominent social norm in the $21^{\text {st }}$ Century (Amelia Book Company, 2017). The impact of video games on children's brains is a fascinating topic that has captured the special attention of numerous researchers. Millions of children play video games for various reasons, ranging from stress relief to entertainment and escapism (Gentile, 2009). Bavelier et al. (2011) report that scientists, including Casey et al. (2005) and Ferguson (2013), while working for the American Psychological Association, sought to ascertain whether playing video games affects children's thoughts, health, and behaviors. Interestingly, some studies report that gaming has beneficial effects on players' hand-eye coordination, while others report a wide range of negative effects. Amidst conflicting reports on the effects of gaming on children's brain based on social isolation and depression, Bediou et al., (2018) have affirmed that video gaming, especially in early ages, could elicit mostly negative psychological effects. For instance, it could trigger deep psychological attachments that lead to isolation from other peers. This puts the social lives and skills of such children at risk of low development and can even lead to depression (Lancy \& Grove, 2017). Kim and Ahn (2016) reinforce these findings by noting that playing games with an 'escapist' mindset and doing so to ignore one's problem makes a person more susceptible to negative effects of playing games such as depression and social isolation. It is against this backdrop that this thesis paper uses secondary data to evaluate effects of gaming on children's brains, in regard to social isolation and depression.

When children give so much of their lives to these virtual worlds, children are missing out on critical social experiences in the real world that help them to develop as social beings 
(Dunckley, 2016). Given that the bar of stimulus from gaming has been proven to reach a threshold so high that almost no other behavior or activity competes for some people, some children are now rejecting the once popular extracurricular activities that allow for them to make new friends and socialize in favor of additional time in virtual worlds.

\section{Purpose of Study}

This research is purposeful in collecting information that will create a well-argued pool of knowledge on the effects of gaming on children's brain. It seeks to demystify available psychological research by Granic, Lobel, and Engels, (2014) showing that video games are beneficial to brain development among children. On the contrary, intensive research by Sunderland (2016) and Patterson (2016) supports that video games negatively impact the reward system of the brain. In particular, Horvath, Misra, Epner, and Cooper (2018) attribute addiction to gaming among children with a set of neurotransmitters known as excitatory. These neurotransmitters work collectively with inhibitory neurotransmitters such as gammaaminobutyric acid (GABA) as well as glutamate, serotonin, norepinephrine, and dopamine causing addiction to gaming. This creates a situation where a child becomes dependent on games, thus prompting them to isolate themselves from their peers (Horvath et al., 2018). Such knowledge is important to parents, phycologists and regulators to design policies that will reduce the negative impact of gaming on children. As noted by Sunderland (2016), this research will help parents to raise children who are happy and have emotional balance.

\section{Scope and Research Questions}

The scope of this thesis is limited to the need to identify and discuss the effects of gaming on the development of a child's brain. It seeks to determine how gaming triggers isolation and depression among children by addressing the question "Does excessive gaming affect children's brains to the extent that it triggers social isolation and depression?"

This study aims to test the following hypotheses:

H1: Gaming affects children's brains by causing social isolation

Null hypothesis 1: Gaming does not affect children's brains by causing social isolation

H2: Gaming affects children's brains by causing depression

Null hypothesis 2: Gaming does not affect children's brains by causing depression

\section{History of Gaming}

\section{LITERATURE REVIEW}

Commercial gaming was discovered in the 1950s through a technology and science exhibition (Spring, 2015). It has since blossomed into a multi-billion entertainment industry. The growth and significance of video gaming have been escalated further with the advancement in information technology and mobile technology which enhances more interconnectedness between and among video players. The new generations of gamers are more mobile and competitive, given that technologies such as the internet provide easy access to scorecards and other data that make the games more competitive and enticing to the youths. Fisch (2013) notes that as the games continue to be more attractive and involving, so is the chance of becoming addicted. Examples of the modern generation of video games are Angry Birds and Candy Crush which are enjoyed by more than $42 \%$ of American gamers (Champion, 2016). Originally, the games were simple, and it focused more on simulations. The games became commercialized and made mainstream in the 1970s and 1980s. The slow growth was coupled with slow technological advancements whereby in the 1980s, gaming consoles such as controllers, joysticks, and buttons were being produced for arcade games. This included the evolution of first generation home consoles which supported a popular game known as Pong (Spring, 2015). Likewise, innovations were made to computer screens and the games to 
accommodate high visual quality. Mainframe computers became more accommodative of video games in the 1970s.

Gaming arose from humble beginnings with the incredibly small market volume of only $\$ 100$ million in the aftermath of the infamous video game crash of 1982-1983 when former Japanese toy corporation Nintendo introduced their breakthrough home console to international markets known as the Famicom (Dunckley, 2016). Gaming's multi-decade transition: demographics, technology and experiences. In response to the fact that the technology supporting home consoles throughout the late 1980s and early 1990s limited the amount of content present in any one game, the difficulty increased per level and sheer skill acquired through repetitive trial and error was the only way one could successfully finish (Desjardins, 2017). In an era where high scores once dominated the social hierarchy of the medium, it now became more important to witness endings and credit rolls to experiences that claimed so much of one's time and effort in order to brag about the accomplishments to friends.

Upon the beginning of the 3-D era which first became prominent in the late 1990's with the introduction of the Sony PlayStation, Nintendo 64, and the Sega Dreamcast, games began to steer away from extreme levels of difficulty and started to focus more on discovery, puzzles, problem-solving, and role-playing mechanics in order to extend the time investment (Desjardins, 2017). This formula has been taken to an extreme in the modern era of gaming, as the vast majority of Triple A titles no longer require significant skills or capabilities to complete and are permeated with little more than mindless, time-wasting activities designed to trigger the brain's needs for progression (Nichols, 2017). Due to the fact that false challenges are so easy to complete yet satisfy the same region of the brain, more and more cases that support the notion of game addiction have been publicized in the past ten years (Nichols, 2017).

The culture became widespread in the 1980s when video gaming evolved into a popular culture. Among the earliest games is Space War which attracted many teenagers. This era was referred to as the golden age of arcade video games. The period lasted from 1978 to 1982 . Spring (2015) connotes that video arcades were available as coin-operated machines in malls. Afterward, there was the emergence of inexpensive home gaming consoles; for example, Intellivision and Atari 2600. These were used at home through televisions. In the 1980s, additional developments were made, and this led to the emergence of LCD games and gaming computers. The second generation of video gaming was reported between 1976 and 1992 while the third generation was from 1983 up to 1995 (Champion, 2016). The fourth generation was evident between 1987 and 1999.

The fourth-generation games were characterized by diminishing use of arcades in favor of newer consoles, with 3D interfaces supporting 16-bit game models. The fifth-generation games ranged from 32-bits to 64-bits and the period ran from 1993 to 2006 (Champion, 2016). Mobile gaming was also developed in this period. Sixth-generation video games were developed between 1998 to 2013, and they triggered the revival of online and mobile gaming. Seventh- generation games were developed between 2005 and 2012 (Spring, 2015). This period was characterized by extensive developments in budget games, which had more effective and efficient cinematic graphics. It is during this era that the Wii console was introduced in the market. The gadget enabled gamers to control gaming actions using real-life movements.

The eighth-generation games were developed in 2013. PC gaming has also been one of the most preferred in Europe and Asia (Champion, 2016). The eighth-generation gaming has been 
improved using cloud storage, mobile gaming, and smartphones, which have increased accessibility and convenience of playing large capacity games (Spring, 2015). The simplicity of accessing video games in the modern era means a more significant threat since more children are becoming addicted to video gaming.

\section{Effect on Children who were Initially Socially Shy}

A study by Gentile et al., (2011) published in the journal "Pediatrics" presents great insight into the effect of gaming on initially socially shy children. After researching thousands of students in Singapore, where participants varied regarding age groups and grade level, over a period of two years, the researchers established that children who were impulsive, less socially apt and less comfortable with other children, spent more time playing video games. The assertion points to a high dependence on video games as a form of leisure. When children played 31 hours, nearly a full work week of video games, compared to nearly half for other students, the results indicated a higher likelihood of suffering from social anxiety, depression and other general phobias (Gentile et al., 2011). Continual and repeated exposure to the internet further contributed to the higher likelihood of depression nine months after the study. Allahverdipour et al., (2010) note that teenagers who experience social challenges always use gaming as a way to manage the problems they face. However, these approaches may increase their depression and isolation from their families and peers.

These findings resonate with studies by other researchers such as Joelving (2011), Amso and Scerif (2015). The authors collectively report that the modern generations of children spend more than seven hours of their day on electronic gadgets, including using video games; $97 \%$ of the teens in the age groups of 12 and 17 play video games on a daily basis. This creates an overdependence on gaming as a form of social relief. In the long run, these social behaviors affect the brain development, thus leading to increased need for isolation due to a resultant social anxiety disorder or social phobia. This situation could also be associated with perceived addiction (Bohmann \& Schupp, 2016). The result is that gaming becomes an excuse for initially socially shy children to avoid social gatherings or face-to-face interactions. This form of social isolation creates more social challenges as the teenagers become more involved in the game than fighting their fear of socializing. In the long run, shy children realize that the games cannot help them solve their mental challenges. The realization that they are victims of anti-social behaviors creates a sort of depression. This could create further withdrawal and isolation, thus creating tendencies of suicidal thoughts or other self-harming behaviors (Nakamuro, Inui, Senoh, and Hiromatsu, 2015). Some researchers have linked social isolation to possible changes in mental attitude of a child. Many children who play violent games tend to develop aggressive tendencies. This argument is however contentious, given that it is hard to differentiate whether violence among children is merely caused by environmental factors or the effects of gaming on the brain.

\section{How Video Games Lead to Social Isolation and Depression}

Despite the negative impacts on physical and mental health, perhaps the most significant danger posed on modern children by video games is the capacity for social isolation. Although that is not nearly as much of a problem as many experts claim due to the fact online multiplayer games facilitate a more seamless avenue of communication and cooperation, it has been observed that the genre most responsible for spawning introverts and removing children from being active members of their real community is the form of single player role playing games (RPG's) (Levine, 2015). Bevelier et al. (2011) lament that studies done in the past giving contradictory findings on the impact of games on depression and social isolation are rather confusing. They note that the truth is that video games could potentially lead to depression and social isolation. As much as there are benefits attributed to gaming, such as improved visual 
acuity, enhanced visuospatial capacity, decision making, object tracking and task switching, which are all connected to enhanced brain's ability to discern and make decisions, gaming is by itself addictive (Han-Ting et al., 2012). A comparison between children gamers and nongamers identified that gamers had more tendencies to be depressed. This was a result of altered social behaviors to accommodate their compulsive gaming habits. This creates the feeling of loneliness and depression.

Horvath et al. (2018) describe this situation as developing a relatively high rate of co-morbid psychiatric illness similar to people with internet addiction. This illness is associated with bipolar disorder, anxiety spectrum disorder, depressive disorder, and attention deficit hyperactivity disorder (ADHD). Gaming is also a prime culprit for indirectly what has been coined 'electronic screen syndrome.' Bavelier et al., (2011) point out that time spent while playing games deprives a person the much-needed time to engage in outdoor social activities. In accordance with reports issued by the Center for Disease and Control and Prevention, more than 18 percent between the ages of 12 to 19 are considered morbidly obese. Excessive sitting and playing indoors without any physical activity is one of the many critical factors responsible for this gaming epidemic (Dunckley, 2016). This also increases social isolation and depression.

Heavy game playing creates anti-social behaviors among children who instead learn new skills, especially aggression from the games. In addition to exacerbating a child's fight or flight response, excessive gaming can induce what is known as 'dysregulation', or the inability to regulate one's moods, attention, or arousal level in order to properly match the surrounding environment (Paturel, 2014). This is especially dangerous for children already prone to fear with respect to past of future situations. Although overstimulation can occur regardless of what is being presented to the child on an electronic screen, gaming and its' detriments can be even more severe when riddled with extraordinary events that could never happen in the real world (Paturel, 2014).

At times, the games trigger a change in cognition in that children become less empathetic, although they show reduced stress after observing anti-social actions. This creates a chance for developing disruptive and confrontational behaviors when engaging with real-life friends. Drastic changes in behavior tend to push away friends, thus leading to isolation. At the same time, Amso and Scerif, (2015) argue that isolation creates higher dependence on gaming, which generates a special destructive class of social burdens and negative neurological changes. Children with a propensity for anxiety tend to foster worries and fears about stories or fictitious beliefs in their head instead of steering towards the reality that is in front of them. Although gaming provides the quintessential escape from constant concerns, it removes them from reality completely over time (Paturel, 2014).

\section{Allegedly Beneficial Effects of Videogames}

Despite most studies stressing the negative effects of videogames on children's physical and mental health, a small body of research has recently emerged which suggests that videogames can help strengthen a wide range of desirable skills and abilities. As Granic et al. (2016, p. 68) point out, action videogames such as Grand Theft Auto and Halo - which are commonly believed to be violent and unsuitable for children - are likely to improve players' mental rotation skills, visual processing abilities and attentional control. To support their claims, the researchers mention a previous fMRI study by Bavelier et al. (2012), which revealed that the mechanisms that determine what things people choose to focus on and ignore were more active during a demanding pattern-detection task in gamers than non-gamers; in view of these findings, the researchers concluded that "shooter" videogames encourage people to use their attentional resources in a more efficient manner. Prensky (2012) even went so far as to argue 
that frequent exposure to videogames has changed the way in which today's children and adolescents solve problems, pointing out that while previous generations were taught to learn through linear instructions, current generations are being taught to learn and solve problems through experimentation - as videogames require players to learn from their mistakes and try different approaches in order to win. Despite researchers' efforts to demonstrate that videogames can have positive effects on players' mental health, it is important to keep in mind that as of today, nobody has been able to determine whether videogames strengthen players' mental skills or players with exceptional mental skills are more likely to be drawn to videogames.

\section{METHODOLOGY}

This study relies on secondary data to determine whether videogames cause children to suffer from social isolation and depression. Secondary research involves collecting information that has previously been presented through primary research. It is a common approach in psychological studies as it has been applied by Bohmann and Schupp, (2016) in their research. Secondary research involves gathering already compiled and analyzed information. A person using the secondary information only needs to arrange it in a manner that is easy to use and interpret. Its other advantages include using information that is readily available, which reduces possible costs. Secondly, secondary research helps in guiding the focus of a study. Thirdly, some research questions - like the one being investigated - can only be addressed by collecting large amounts of data and analyzing multiple variables (Matthews \& Ross, 2014). However, secondary data makes it possible for researchers to gather reliable information from government-sponsored sources where such experiments and reports are made in conformity with high standards of regulation and moderation, thus saving both time and money.

Secondary data was collected using four main techniques. The first step was to identify the main topic of study (Panneerselvam, 2014). The topic is to evaluate the effects of gaming on children's brains regarding social isolation and depression. The second technique relates to gathering existing information and data on the subject of interest (Matthews \& Ross, 2014). Data was collected primarily from peer-reviewed journals, credible online sources, and psychology magazines among other professional literature sources. This step was followed by a comparison of data from primary sources. These sources focused on explaining effects of gaming on children's brain based on depression and social isolation.

The primary criterion for selecting these sources included prioritizing peer-reviewed journal articles. In order to gather reliable secondary data, the author relied on online databases such as Jstor and ProQuest and reputable psychology websites to find a sufficient number of articles related to this study's research question. The fourth technique was to review the articles and select the ones that explored the effects of videogames on children's mental health and social behavior. The analysis was done by first, searching internet sources by including keywords such as social isolation, depression, gaming and child's brain. This helped to narrow down search results. Secondly, skimming proved useful in narrowing down the scholarly articles identified (Panneerselvam, 2014). The articles that remained were analyzed in detail through intensive reading and comparison, after which the information derived was compiled as results and findings. As can be seen from the table below, the final sample consisted of eight articles. 
Table 1. Sample

\begin{tabular}{|l|l|}
\hline Study / article & Source \\
\hline Lancy \& Grove (2017) & American Journal of Play \\
\hline Gentile et al. (2011) & Pediatrics \\
\hline Patterson (2016) & The Brain on Stress (Book) \\
\hline Casey et al. (2005) & Trends in cognitive sciences \\
\hline Uz \& Cagiltai (2015) & Digital Education Review \\
\hline Bediou et al. (2018) & Psychological Bulletin \\
\hline Cole and Griffiths (2007) & CyberPsychology \& Behavior \\
\hline Platt et al. (2013) & Depression and anxiety \\
\hline Sojourner (2011) & Psychology Today \\
\hline Jones et al. (2014) & Frontiers in Psychology \\
\hline Allahverdipour et al. (2010) & BMC Public Health \\
\hline
\end{tabular}

\section{RESULTS}

The sample consisted of eleven studies that explored the impact of videogames on children's mental health and social lives. A key consideration was devoted towards discussing effects of video games on the development of the child's brain while considering aspects of social isolation and depression. The data collected was guided by the need to either credit or discredit two hypotheses. Hypothesis one (H1) states that gaming affects children's brains by causing social isolation, and (H2) posits that gaming affects children's brain by causing depression. As the table below suggests, out of eleven studies, six were found to support hypothesis 1 , five were found to support hypothesis 2 , four supported null hypothesis 1 , and only one supported null hypothesis 2 .

Table 2. Articles / studies' stand in relation to the research hypotheses

\begin{tabular}{|c|c|c|c|c|}
\hline Study / article & H1 & H2 & null H1 & null H2 \\
\hline Lancy \& Grove (2017) & 1 & 0 & 0 & 0 \\
\hline Gentile et al. (2011) & 1 & 1 & 0 & 0 \\
\hline Patterson (2016) & 1 & 1 & 0 & 0 \\
\hline Casey et al. (2005) & 0 & 0 & 1 & 0 \\
\hline Uz \& Cagiltai (2015) & 0 & 0 & 1 & 0 \\
\hline Bediou et al. (2018) & 1 & 0 & 0 & 0 \\
\hline Cole and Griffiths (2007) & 0 & 0 & 1 & 0 \\
\hline Platt et al. (2013) & 0 & 1 & 0 & 0 \\
\hline Sojourner (2011) & 1 & 1 & 0 & 0 \\
\hline Jones et al. (2014) & 0 & 0 & 0 & 1 \\
\hline Allahverdipour et al. (2010) & 1 & 1 & 0 & 0 \\
\hline
\end{tabular}

As supported by secondary data collected, it can be affirmed that gaming affects the development of children's brains. Mostly, it isolates children from their peers, which triggers long-term feelings of depression (Sojourner, 2011). Such isolation could lead to mental disorders associated with increased anxiety and depression. This trend is attributed to selfmediated games which are considered dangerous.

Sojourner (2011) connotes that if a child plays a game with an escapist mindset, whereby their main focus is on ignoring problems, avoiding unpleasant emotions, and avoiding stressful situations, then such a child will likely suffer from depression, social isolation or anxiety associated with video games. The impact of video games on children's brain can be explained based on their ability to activate certain parts of their brain. This includes; the parts of the brain that process the visual information and the parts that perform motor functions. Studies have also identified that gaming has an impact on the medial forebrain, which is linked to the 
pleasure circuits. This includes the nucleus accumbens and amygdala, as well as the orbitofrontal cortex (Linden, 2011). Whereas both girls and boys show the same activation of these brain regions, boys showed a significantly stronger level of pleasure associated with gaming. This created a higher chance of isolation and depression in boys than in girls.

Amso and Scerif (2015) add that video games activate pleasure circuits to a certain degree, which leads to impulsive behavior that derails children from engaging in active social lives. Scientists are convinced that games create a pleasure associated with goal fulfillment. A scan of brains involved in gaming using positron emission tomography (PET) showed that playing tank-driving video games increases dopamine (Linden, 2010). These chemicals have been associated with video game addiction in children. In a more detailed explanation of how the brain functions, Horvath et al. (2018) attribute addiction to video games among children with a set of neurotransmitters known as excitatory. When these neurons are activated, they create an action potential.

Additionally, the human brain has another set of neurons known as inhibitory, which prevent other neurons from transmitting an action potential. The most effective and common excitatory neurotransmitter in the human brain is known as glutamate while the most common inhibitory neurotransmitter is gamma-aminobutyric acid (GABA). Both glutamate and GABA play an important part in children addiction to games. Other neurotransmitters that influence addiction include; serotonin, norepinephrine, and dopamine (Horvath et al., 2018). There are also larger neuropeptides and neuromodulators that influence addiction process. Common neuropeptides associated with games addiction include stress hormones, peptide associated with anxiety and feeding and endorphins (Kim \& Ahn, 2016). This explanation and discussion justify why video gaming could become addictive, thus creating social isolation which leads to anxiety and depression.

An article titled "Do Video Games Make Kids Saints or Psychopaths?" describes the connection between video games, isolation and depression (Barclay, 2014). Based on the narration, it is possible to argue that isolation comes before depression sets in. For instance, on December 14, in 2012, Adam Lanza, a 20-year-old shot his mother, before proceeding to Sandy Hook Elementary School where he killed 26 people, among them, children and teachers. He then committed suicide. An investigation into the matter revealed that Lanza suffered from Asperger's syndrome and was a dedicated video game player (Park, 2014). His preference was violent games such as Call of Duty, Grand Theft Auto and mostly Mario Kart (BBC, 2017). In response to those who blamed Adam's actions on his mental disorder, experts made it clear that Asperger's syndrome does not encourage violence, meaning that the tragic event must have been triggered by other factors (Park, 2014). As the research noted, violent games were associated with the development aggression among players, while increasing their feeling of hostility. In fact, the games desensitize a person and make them perceive violence as normal. At the same time, the isolation accompanied by spending long hours of the day on the game derails a person from living a normal life. This creates opportunities for development of depression over a prolonged period of time. The speed of developing depression is determined by the personality of a person, where those suffering from Asperger's syndromes such as Lanza could easily drift into depression, compared to children with more outstanding personalities. This result findings therefore detail the way gaming triggers social isolation, which stimulates depression tendencies thus leading a person into becoming suicidal. 


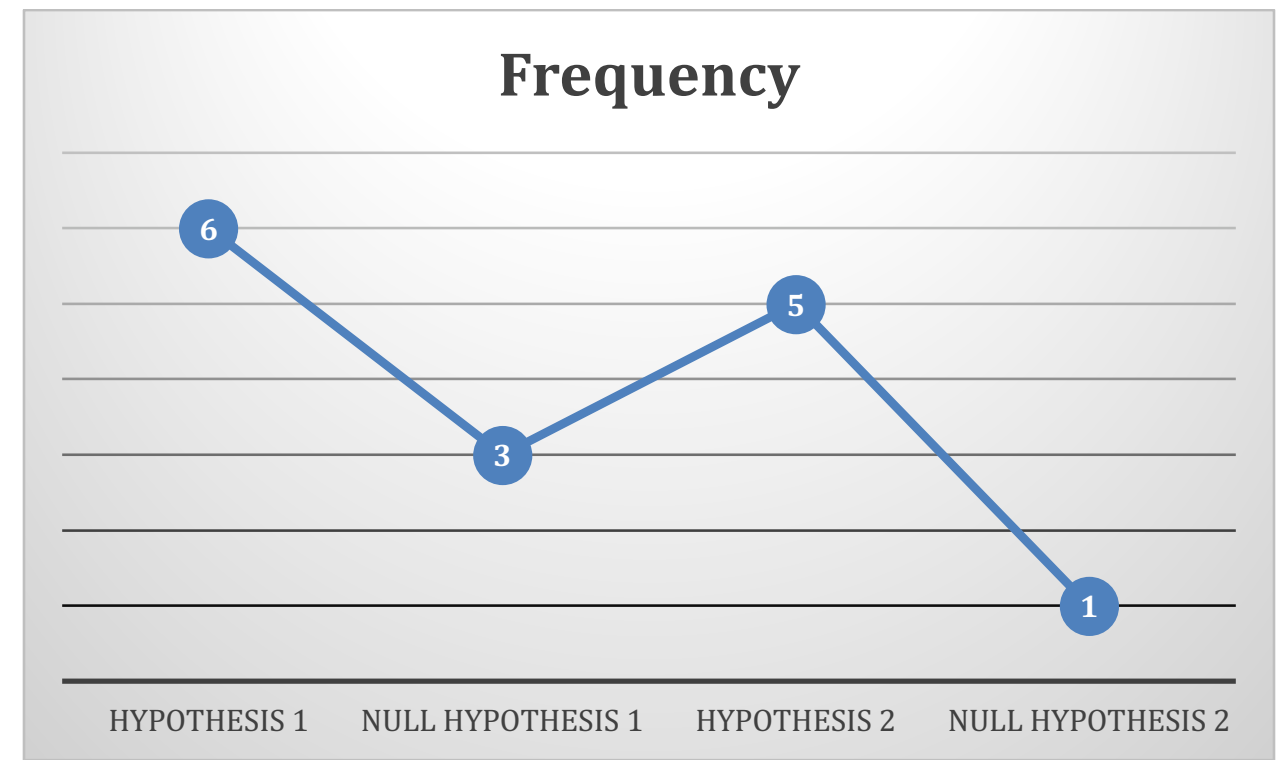

Graph 1. Number of studies supporting each hypothesis / null hypothesis

Overall, as the above graph suggests indicates, six out of eleven articles / studies support the hypothesis that excessive gaming causes social isolation, thus making hypothesis 1 the most credible one; hypothesis 2 is backed by five out of eleven articles / studies, meaning that available evidence strongly supports the claim that excessive gaming is strongly correlated with depression. Gentile et al. (2011), for instance, found that pathological gamers are likely to experience depression $(\mathrm{R} 2=0.49)$, anxiety $(\mathrm{R} 2=0.29)$ as well as social phobias $(\mathrm{R} 2=0.20)$. Similarly, Allahverdipour et al. (2010) found that children who regularly play videogames $(n=68)$ are more likely to experience severe depression (Mean: 1.73; SD: \pm 2.3 ) and social dysfunction (Mean: 1.53; SD: \pm 1.7) than non-gamers ( $n=24$; Mean: 2.12; SD: \pm 2.5 for severe depression and Mean: 2.38; SD: \pm 2.0 for social dysfunction). As for the null hypothesis, three out of eleven articles support null hypothesis 1 and only one supports null hypothesis 2 , which is the least credible one. Analyzing the impact of multiplayer online videogames on players' social lives, Cole \& Griffiths (2007) found that a significant percentage of male players (7.7 versus $3.1 ; t=3.06, p=0.002$ ) had managed to make good friends thanks to videogames, even though female players were more likely to meet their online friends in real life (7.7 versus 3.1; $t=3.06, p=0.002$ ). Furthermore, a significant percentage of players claimed to have discussed sensitive issues with their online friends, with female players being more likely to talk about loss, family problems, work problems and sexuality-related matters than male players (7.7 versus 3.1; $\mathrm{t}=3.06, \mathrm{p}=0.002$ ).

\section{DISCUSSION}

These research results present an important insight that answers pertinent questions on whether gaming has negative impacts on the child's brain and whether such impact could lead to isolation and depression. As elaborated in this research paper, it is certain that parents, social policy makers, children department and clinicians should be worried about this trend. They need to ensure that they regulate their children's indulgence in gaming to protect them from the adverse and potentially long-lasting adverse effects of gaming. As explained in the results section, intensive gaming could create a situation where a child becomes shy and avoids social events and becomes excessively dependent on games as a source of pleasure. This prompts them to isolate themselves, thus increasing the chances of depression (Horvath et al., 2018). This knowledge is important to parents since they need to understand the effect of games on their children. Guided by this understanding, they need to limit the intensity of gaming among their children to raise happy and emotionally balanced children. 
Future researchers need to be aware of these findings and thus, focus on a more detailed analysis of differences in brain's response to gaming among boys and girls. This will help answer the emerging question of whether gaming has a similar effect on boys and girls. Such knowledge is important to all those who are involved in children's development and care - e.g. parents, psychologists, educators, physicians, legal guardians and policymakers. Policymakers, in particular, are ideally positioned to design policies that will encourage socialization to reduce depression among children. Clinicians and counselors also need to understand the connection between gaming and depression to give accurate and useful treatment and counseling services, respectively. In view of the findings presented in the previous section, it can be inferred that available evidence strongly supports hypotheses one and two, whereas only a limited number of studies seem to associate videogames with improved social skills and decreased depression. With more and more children turning to videogames as a source of entertainment and distraction, it is strongly recommended that researchers keep investigating the effects of gaming on children's mental health and social lives in further depth. Even though a small body of literature has emerged which argues that videogames are not as harmful as most psychologists make them out to be, there is a large amount of hard evidence indicating that videogames play a key role in ruining children's mental health and social lives. This should be a good enough reason for policymakers to develop ad hoc measures aimed at regulating the videogame industry and raise awareness about the negative effects of excessive gaming.

\section{RESEARCH LIMITATIONS}

As much as secondary research was admirable for this research, its' use was limited by the following factors. First, the information presented in secondary sources was too wide and diverse. This made it hard to identify specific information of interest. The process was timeconsuming and potentially led to the collection of poorly researched or presented data (Panneerselvam, 2014). Secondly, some of the secondary data were bound to be outdated or of low quality. In analyzing video games, information that was available two decades ago might be less significant given the changes in technologies where current generations of children and youths have easy access to mobile games and more advanced gaming consoles (Panneerselvam, 2014). These challenges were however addressed through careful identification of information. For instance, most of the sources used were from peer-reviewed journals.

\section{CONCLUSION}

This thesis paper identifies a connection between video gaming and the development of depression, and social isolation among children. It acknowledges that as much as video games could be associated with some benefits if properly regulated, it could also be disadvantageous to children as it could trigger a change in brain properties, thus leading to psychic disorders such as depression. It is therefore important that parents support their children emotionally to avoid the development of an escapist mindset. In order to ascertain this statement, a research was conducted using secondary sources of data to affirm two sets of hypothesis. The first hypothesis argued that gaming affects children's brains by causing social isolation and depression while (H2), posited that gaming did not affect children's brain by causing social isolation and depression. The findings created awareness on the fact that gaming affected the chemical components in the brain; for instance, the inhibitory neurotransmitters such as gamma amino butyric acids (GABA) and glutamate, serotonin, norepinephrine, and dopamine, which cause addiction to gaming. Additionally, children who are addicted to gaming always become withdrawn from social events and friends. The behavior increases their chances of developing depression. The research is important to parents, clinicians, counselors, and children departments, among other stakeholders since it helps to set policies and guidelines that promote healthier childhood. Overall, this study has demonstrated that even though 
videogames may play a role in enhancing certain mental skills and abilities, the negative effects of excessive gaming significantly outweigh their benefits. In light of these considerations, it is crucial that educators, parents and policymakers take action to minimize children's exposure to potentially harmful videogames.

\section{References}

Allahverdipour, H., Bazargan, M., Farhadinasab, A., \& Moeini, B. (2010). Correlates of video games playing among adolescents in an Islamic country. BMC public health, 10(1), 286.

Amso, D., \& Scerif, G. (2015). The attentive brain: insights from developmental cognitive neuroscience. Nature Reviews Neuroscience, 16(10), 606-619.

Barclay, R. (2014). Do Video Games Make Kids Saints or Psychopaths (and Why Is It So Hard to Find Out)? Available at: https://www.healthline.com/health-news/video-games-saints-or-psychopaths-082814\#1

Bavelier, D., Green, C. S., Han, D. H., Renshaw, P. F., Merzenich, M. M., \& Gentile, D. A. (2011). Brains on video games. Nature reviews neuroscience, 12(12), 763-768.

Bavelier, D., Green, S., Han, D., Renshaw, P., Merzenich, M., \& Gentile, A. (2011). Brains on video games. London: Macmillan Publishers Limited.

Bavelier, D., Achtman, R. L., Mani, M., \& Föcker, J. (2012). Neural bases of selective attention in action video game players. Vision Research, 61, 132-143.

BBC. (2017). Sandy Hook shootings: Four things revealed by FBI files. Available at: http://www.bbc.com/news/world-us-canada-41749336

Bediou, B., Adams, D. M., Mayer, R. E., Tipton, E., Green, C. S., \& Bavelier, D. (2018). Meta-analysis of action video game impact on perceptual, attentional, and cognitive skills. Psychological Bulletin, 144(1), 77.

Bohmann, S., \& Schupp, J. (2016). IT and communication technologies dominate adolescent downtime. DIW Economic Bulletin, 6(48), 558-567.

Casey, B. J., Tottenham, N., Liston, C., \& Durston, S. (2005). Imaging the developing brain: what have we learned about cognitive development? Trends in cognitive sciences, 9(3), 104-110.

Champion, E. (2016). Critical Gaming: Interactive History and Virtual Heritage. New York: Routledge.

Cole, H., \& Griffiths, M. D. (2007). Social interactions in massively multiplayer online role-playing gamers. CyberPsychology \& Behavior, 10(4), 575-583.

Fisch, S. M. (2013). Cross-Platform Learning: On the Nature of Children's Learning from Multiple Media Platforms. New directions for child and adolescent development, 2013(139), 59-70.

Gentile, D. A. (2009). Video games affect the brain—for better and worse. Cerebrum: The DANA Foundation. Available at:

http://www.dana.org/Cerebrum/2009/Video Games Affect the Brain\%E2\%80\%94for Better and Worse/

Gentile, D., Choo, H., Liau, A., Sim, T., Li, M., Fung, D. \& Khoo, A. (2011). Pathological Video Game Use among Youths: A Two-Year Longitudinal Study. Pediatrics, 127 (2), 11(7)

Granic, I., Lobel, A., \& Engels, R. C. (2014). The benefits of playing video games. American Psychologist, 69(1), 66.

Han-Ting, W., Mu-Hong, C., Po-Cheng, H. \& Ya-Mei, B. (2012). The association between online gaming, social phobia, and depression: an internet survey. BMC Psychiatry, 2 (12), 92.

Horvath, T., Misra, K., Epner, A. \& Cooper, M. (2018). Addiction Changes the Brain's Chemistry. Available at: https://www.risas.org/poc/view doc.php?type $=$ doc\&id $=48371 \& \mathrm{cn}=1408$

Joelving, F. (2011). Do video games fuel mental health problems? Available at:

https://www.reuters.com/article/us-video-games/do-video-games-fuel-mental-health-problemsidUSTRE70G29M20110117

Jones, C.M. et al. (2014). Gaming well: links between videogames and flourishing mental health. Available at: https://www.frontiersin.org/articles/10.3389/fpsyg.2014.00260/full

Kim, H. H. S., \& Ahn, S. J. G. (2016). How does neighborhood quality moderate the association between online video game play and depression? A population-level analysis of Korean students. Cyberpsychology, Behavior, and Social Networking, 19(10), 628-634. 
Lancy, D. F., \& Grove, M. A. (2017). Marbles and Machiavelli: The role of gameplay in children's social development. American Journal of Play, 3(4).

Linden, D. (2011). Video Games Can Activate the Brain's Pleasure Circuits. Available at: https://www.psychologytoday.com/blog/the-compass-pleasure/201110/video-games-can-activate-the-brainspleasure-circuits-0

Matthews, B., \& Ross, L. (2014). Research methods. London: Pearson Higher Ed.

McGinty, E. E., Webster, D. W., Jarlenski, M., \& Barry, C. L. (2014). News media framing of serious mental illness and gun violence in the United States, 1997-2012. American journal of public health, 104(3), 406-413.

Nakamuro, M., Inui, T., Senoh, W., \& Hiromatsu, T. (2015). Are television and video games really harmful for kids? Contemporary Economic Policy, 33(1), 29-43.

Panneerselvam, R. (2014). Research methodology. New York: PHI Learning Pvt. Ltd.

Park, A. (2014). Don't Blame Adam Lanza's Violence on Asperger's. Available at: http://time.com/19957/adamlanzas-violence-wasnt-typical-of-aspergers/

Patterson, M. (2016). The Brain on Stress. Seattle: New Have Press.

Platt, B., Kadosh, K. C., \& Lau, J. Y. (2013). The role of peer rejection in adolescent depression. Depression and anxiety, 30(9), 809-821.

Prensky, M. (2012). From digital natives to digital wisdom: Hopeful essays for 21st century

learning. Thousand Oaks, CA: Corwin Press

Sojourner M. (2011). Video Gaming can cause depression, anxiety, and social phobia. Available at: https://www.psychologytoday.com/blog/she-bets-her-life/201101/video-gaming-can-cause-depression-anxietyand-social-phobia-2

Spring, D. (2015). Gaming history: Computer and video games as historical scholarship. Rethinking History, 19(2), 207-221.

Spring, D. (2015). Gaming history: Computer and video games as historical scholarship. Rethinking History, 19(2), 207-221.

Sunderland, M. (2016). The Science of parenting: How today's brain research can help you raise happy, emotionally balanced children. London: Penguin.

van der Meulen, M., van IJzendoorn, M. H., \& Crone, E. A. (2016). Neural correlates of prosocial behavior:

Compensating social exclusion in a four-player cyber ball game. PloS 